\title{
Anti-IgE autoantibodies in systemic sclerosis (scleroderma)
}

\author{
LEE D KAUFMAN, ${ }^{1}$ BARRY L GRUBER, ${ }^{1}$ MARY J MARCHESE, ${ }^{1}$ AND \\ JAMES R SEIBOLD ${ }^{2}$
}

From the ${ }^{1}$ Department of Medicine, Division of Allergy, Rheumatology, and Clinical Immunology, State University of New York at Stony Brook, Stony Brook, New York; and the ${ }^{2}$ Department of Medicine, Division of Rheumatology, University of Medicine and Dentistry of New Jersey, Robert Wood Johnson Medical School, New Brunswick, New Jersey

SUMmARY An enzyme immunoassay was used to determine the prevalence of anti-IgE autoantibodies in 66 patients with systemic sclerosis (scleroderma) stratified according to extent and duration of disease. Serum IgG anti-IgE antibodies were detected in $14(21 \%)$ patients and IgM anti-IgE antibodies in nine $(14 \%)$ patients. The overall prevalence of IgG or IgM isotypes was 21/66 (32\%). Anti-IgE autoantibodies were not found in six patients with undifferentiated connective tissue disease or two patients with eosinophilic fasciitis. Attempts to demonstrate histamine release from basophils in vitro by using serum samples containing high titre anti-IgE antibody were unsuccessful. By multivariate analysis the presence of anti-IgE antibody was not associated with duration of systemic sclerosis; extent of scleroderma; specific visceral features, including heart, lung, renal, and gastrointestinal involvement; or mortality.

Recent studies have focused attention on the potential role of mast cells in the pathogenesis of systemic sclerosis (scleroderma) and other similar fibrosing syndromes. ${ }^{1}$ An increased density of dermal mast cells has been described in patients with scleroderma ${ }^{2}$ the toxic oil syndrome, ${ }^{3}$ graft versus host disease, ${ }^{4}$ and in the tight skin mouse model of scleroderma. ${ }^{5}$ Furthermore, the dermal mast cells of tight skin mice show massive degranulation, ${ }^{6}$ and treatment with disodium cromoglycate (an inhibitor of mast cell degranulation) has been observed to produce a marked decrease in skin fibrosis. ${ }^{7}$

Mast cells and circulating basophils may release their inflammatory mediators when activated by lymphocyte products or histamine releasing factors secreted from neighbouring mononuclear cells ${ }^{8}$ also present in the dermis of patients with scleroderma. ${ }^{9}$ After degranulation mast cell granules can be internalised by fibroblasts, and this interaction may then promote local fibrosis. ${ }^{10}$ Anti-IgE autoantibodies, previously reported in systemic lupus erythematosus ${ }^{11}$ and other autoimmune and atopic

Accepted for publication 23 July 1988.

Correspondence to Dr Lee D Kaufman, HSC-T-16-040, Division of Allergy, Rheumatology, and Clinical Immunology, State University of New York at Stony Brook, Stony Brook, New York 11794-8161, USA. disorders, ${ }^{12-15}$ may represent an additional mechanism for activation of mast cells and their subsequent interaction with fibroblasts in scleroderma. The current study sought to determine the prevalence of anti-IgE autoantibodies in a group of patients with scleroderma stratified according to the extent and duration of disease as well as their potential functional activity as determined by an in vitro basophil release assay.

\section{Patients and methods}

\section{PATIENTS}

Sixty six patients fulfilled preliminary American Rheumatism Association criteria for classification as definite systemic sclerosis ${ }^{16}$ and were selected to reflect a balanced stratification of disease extent and duration. Classification as generalised scleroderma required the presence of truncal skin thickening, whereas limited scleroderma described those patients with skin involvement limited to the hands, forearms, face, and feet. Onset of systemic sclerosis was dated from the first non-Raynaud's clinical manifestation, with three years' duration chosen as the divider between those patients with early and those with late systemic sclerosis. ${ }^{17}$ In addition, we studied six patients with undifferentiated connective 
tissue disease (defined as having at least four of the following six features: late age of onset of Raynaud's phenomenon, finger oedema or sclerodactyly, or both, abnormal nail fold capillaroscopic findings, serum anticentromere antibody with a titre $\geqslant 1 / 160$, and laboratory evidence of impaired maximal digital arterial flow or of in vivo platelet activation ${ }^{18}$ ) and two patients with recently diagnosed eosinophilic fasciitis.

All patients underwent a detailed clinical and laboratory assessment as described by the scleroderma criteria cooperative study, ${ }^{16}$ which included chest radiograph, 12 lead electrocardiogram, cineoesophagography, pulmonary function testing, plasma renin activity, 24 hour urine collection for protein excretion and creatinine clearance, and a detailed serological profile. Serum samples were collected and stored at $-70^{\circ} \mathrm{C}$ until needed for assay.

Data were entered on the Medlog clinical data management system, and this system was used for statistical analysis. Fisher's exact and paired $t$ tests were used for univariate analyses and linear regression of least squares or stepwise linear regression model procedures for multivariate analysis. Mean antibody titres among patient subgroups were compared using Student's $t$ distribution for two means (unpaired).

\section{ENZYME IMMUNOASSAY}

Anti-IgE antibodies for both IgG and IgM isotypes were determined by an enzyme linked immunosorbent assay (ELISA) as described by Nawata et $a^{15}$ with minor modifications. Multiwell polystyrene plates (Dynatech Inc, Alexander, VA) were coated with myeloma IgE at $1 \mu \mathrm{g} /$ well in bicarbonate buffer $\mathrm{pH} 9 \cdot 6$. Further blocking of any remaining reactive sites to reduce background was not necessary and, in fact, created false positive reactivity directed against the blocking reagents-for example, bovine serum albumin. The background in these unblocked plates remained less than 0.01 at optical density $405 \mathrm{~nm}$. The plates were stored at $4^{\circ} \mathrm{C}$ and the assay was performed by diluting serum in phosphate buffered saline-Tween. The serum was diluted at 1:10 and $1: 100$ for the IgG anti-IgE and IgM anti-IgE ELISAs respectively and allowed to incubate on the plates overnight at $4^{\circ} \mathrm{C}$. (These dilutions were chosen as the approximate mean along the linear slope of serum concentrations versus optical density plotted in semilogarithmic form.) The plates were then extensively washed with phosphate buffered saline. Alkaline phosphatase labelled goat antihuman IgG or IgM (Fc specific, Cappel Laboratories, Malverne, PA) at 1:1000 dilution was added for two hours and allowed to react with $p$-nitrophenyl

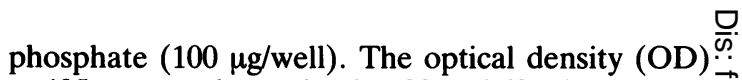
at $405 \mathrm{~nm}$ was determined at 30 and 60 minutes on $\mathrm{a}_{\stackrel{\vec{F}}{\vec{P}}}$ Dynatech ELISA reader. The relative quantity of bound IgG or IgM was calculated using standard $\frac{\mathrm{C}}{0}$ amounts of coupled purified IgG (Miles Laborator- $\overline{\bar{c}}$. ies, Naperville, IL) or IgM (Calbiochem, Summer- $\overparen{\mathbb{\Phi}}$ ville, NJ) ranging from $10 \mathrm{ng}$ to $1 \mu \mathrm{g}$. The data are expressed as a ratio as follows:

$$
\frac{\text { OD } 405 \mathrm{~nm} \text { (sample) }}{\text { OD } 405 \mathrm{~nm} \text { (standard) }} \times \mathrm{ng} \text { of standard }
$$

Positivity was defined as a value greater than two standard deviations from a control group of $22 \%$ healthy, non-atopic individuals. The specificity of this assay has been previously confirmed. ${ }^{11}$

SERUM IgE CONCENTRATIONS

Total serum IgE concentrations were measured by a radioimmunosorbent (PRIST) assay (Pharmacia Diagnostics, Piscataway, NJ).

BASOPHIL STUDIES

Leucocytes were separated from whole blood obtained from non-atopic healthy volunteers and ${ }^{\bullet}$ from selected patients with raised levels of anti-IgE antibodies after informed consent using dextran sedimentation $(0 \cdot 03 \%$ dextran, $0 \cdot 3 \%$ glucose, $0 \cdot 15$ 을 $\mathrm{M} \mathrm{NaCl}$ ) by the method of Lichtenstein and Osler. ${ }^{19} \stackrel{2}{\circ}$ The leucocytes were washed in HEPES buffer $\stackrel{\mathbb{Q}}{\varrho}$ ( $N$-2-hydroxyethylpiperazine- $N^{\prime}$-2-ethanesulphonic $\overrightarrow{\overrightarrow{0}}$ acid) containing $0.03 \%$ human serum albumin and 3 aliquots were incubated at $37^{\circ} \mathrm{C}$ for 30 minutes with serum containing anti-IgE antibodies in HEPES? buffer with $1.5 \mathrm{mM} \mathrm{CaCl}$ and $2.0 \mathrm{mM} \mathrm{MgCl}$. The histamine released was measured in duplicate? samples by the double isotopic radioenzyme assay 3 of Beaven et al. ${ }^{20}$ Commercially obtained goat antihuman IgE (Kirkegaard and Perry Laboratories $ᄋ$ Inc, Gaithersburg, Maryland) was used as a positive control during each basophil release assay and 은 consistently produced histamine release at dilutions $?$ of both $1: 100$ and 1:1000.

\section{Results}

Figure 1 shows the distribution of anti-IgE autoanti- $\mathrm{W}$ bodies by isotype for patients and controls. The overall prevalence of IgG or IgM anti-IgE was $21 \%$ out of 66 patients $(32 \%)$. Of these 66 patients, $14 \nsubseteq$ $(21 \%)$ had IgG anti-IgE and nine $(14 \%)$ had IgM anti-IgE. Two patients had both IgG and IgM $\frac{T}{\circ}$ isotypes. Anti-IgE antibodies were not found in the $\stackrel{\vec{D}}{\mathbb{D}}$ sera from six patients with undifferentiated connec- $\stackrel{?}{\stackrel{P}{Q}}$ tive tissue disease or two patients with eosinophilic $\stackrel{\unrhd}{\varrho}$ fasciitis. Table 1 shows the prevalence of anti-IgE antibodies by isotype for each clinical subset of $\delta$ 


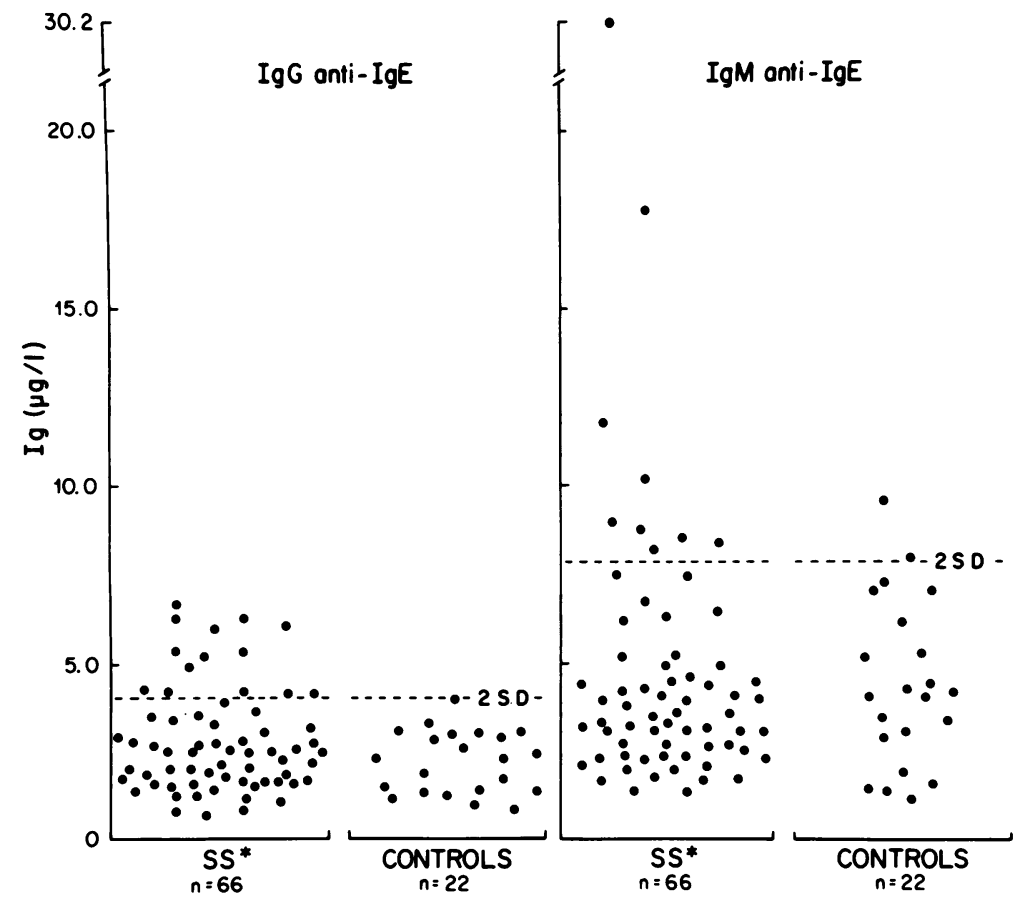

Fig. 1 Anti-IgE autoantibodies by IgG and IgM isotype versus non-atopic controls. ${ }^{*}$ IgG versus controls $p<0.02 ;{ }^{*}$ IgM versus controls $p=N S$. $S S=$ systemic sclerosis.

Table 1 Number (\%) of anti-IgE autoantibodies in systemic sclerosis

\begin{tabular}{lllll}
\hline & $E G^{*}(n=18)$ & $E L^{*}(n=12)$ & $L G^{*}(n=15)$ & $L L^{*}(n=21)$ \\
\hline IgG & $4(22)$ & $3(25)$ & $1(7)$ & $6(29)$ \\
IgM & $2(11)$ & $1(8)$ & $4(27)$ & $2(9)$ \\
Total & $6(33)$ & $3 \dagger(25)$ & $5(33)$ & $7 \dagger(33)$
\end{tabular}

${ }^{*} \mathrm{EG}=$ early generalised; $\mathrm{EL}=$ early limited; $\mathrm{LG}=$ late generalised; and $L L=$ late limited systemic sclerosis.

fOne patient had both IgG and IgM isotypes.

disease. There were no significant differences in the prevalence of anti-IgE antibody of either isotype between patients with early or late and limited or generalised involvement. Furthermore, when the levels of IgG and IgM anti-IgE were compared among the various subsets of patients examined there was no difference between patients with early limited and late limited disease, or between patients with early generalised and late generalised disease. When the total number of patients with generalised disease (early and late) was compared with the total number with limited disease (early and late) the mean antibody titre for IgG was significantly higher in patients with limited disease $(p<0.05)$. The difference between these groups for IgM was not statistically significant.
There was a significant correlation between IgM anti-IgE and total serum IgE concentrations $(R=0.4106 ; p<0.01)$, but no relation between IgG anti-IgE and total serum IgE concentrations $(p=N S)$. In addition, the total mean serum IgE concentration in patients was not abnormal. We were unable to demonstrate the ability of these autoantibodies to degranulate circulating basophils. Normal donor basophils were incubated with varying concentrations of sera containing high titre anti-IgE of both IgG and IgM isotypes in vitro, but multiple attempts to induce the release of measurable histamine failed. Furthermore, heating of reactive sera, which may increase the amount of free antibody available, ${ }^{12}$ also had no significant effect on in vitro histamine release from basophils.

We selected 24 independent variables for multivariate analysis based on suggested associations with anti-IgE antibodies, including patient age, sex, total skin score, clinical estimates of skin oedema, skin biopsy specimen weights, history of pruritus, presence of digital ischaemic ulcerations, tendon friction rubs, serum anticentromere antibody, serum creatinine, thyroid function profiles, presence of ventricular arrhythmia on 24 hour ambulatory electrocardiography, pulmonary involvement including reduced vital capacity or diffusing capacity, or both, chest radiographic evidence of interstitial fibrosis, 
Table 2 Number (\%) of anti-IgE autoantibodies by organ system involved

\begin{tabular}{lclc}
\hline & IgG (n=14) & IgM (n=9) & $\begin{array}{l}\text { IgG or IgM } \\
(n=21)\end{array}$ \\
\hline Heart & $7(50)$ & $3(33)$ & $10(48)$ \\
Lung & $9(64)$ & $4(44)$ & $13(62)$ \\
Kidney & $2(14)$ & $1(11)$ & $3(14)$ \\
Gastrointestinal & $13(93)$ & $7(78)$ & $20(95)$ \\
\hline
\end{tabular}

cine-oesophagography, plasma renin activity, clinical evidence of sicca complex, capillaroscopic classification, treatment with either corticosteroid or $\mathrm{H}_{2}$ blockers, total white blood cell count, haemoglobin concentration, and mortality. We found no significant associations of anti-IgE antibody of either isotype with any of these features of systemic sclerosis. Table 2 presents the distribution of antiIgE antibodies according to major features of visceral involvement.

\section{Discussion}

Mast cells are found throughout connective tissues in a predominantly perivascular location. They possess high affinity IgE receptors, and cross linking of membrane bound $\mathrm{IgE}$ leads to cellular activation and release of multiple inflammatory mediators from intracytoplasmic granules. An increased number of dermal mast cells have been noted in a number of pathological fibrosing conditions, including systemic sclerosis, ${ }^{2}$ graft versus host disease, ${ }^{4}$ and the toxic oil syndrome, ${ }^{3}$ which resembles systemic sclerosis. Furthermore, the tight skin mouse model, which has been compared with human scleroderma, has also been shown to have an abundance of dermal mast cells,${ }^{6}$ and when these mice are treated with an inhibitor of mast cell degranulation (disodium cromoglycate) there is a decrease in the amount of fibrosis. ${ }^{7}$

Whether or not tissue mast cells participate in the development of tissue fibrosis and by what precise mechanism remains uncertain. Nevertheless, in addition to being found at sites of collagen accumulation a number of observations have been made that corroborate their potential role in the pathogenesis of scleroderma. Mast cell degranulation in vitro is associated with fibroblast stimulation and collagen production. ${ }^{21} 22$ Furthermore, mast cell granules are internalised by fibroblasts, ${ }^{10}$ demonstrating that an interaction between the two cell types may exist.

Although mast cell degranulation usually occurs via antigen cross linking of two IgE membrane bound molecules, another potential mechanism for release is the aggregation of $\operatorname{IgE}$ receptors through $\Rightarrow$ the interaction of autoantibodies directed against ${ }^{\circ}+$ membrane bound IgE. The inability to demonstrate? histamine release after exposure of basophils in vitro음 to sera containing these autoantibodies raises ques- $-\frac{N}{\sigma}$ tions about the significance of their presence. $\stackrel{\otimes}{\Omega}$ Several factors may play a part in the functionalos activity of anti-IgE antibodies. Differences in the $\overrightarrow{-}$ responsiveness of mast cells and basophils to various: secretagogues have been noted ${ }^{23}$ and may explain $\vec{\omega}$ why basophils could not be activated in our study. Recent evidence in some patients with systemic lupus erythematosus ${ }^{11}$ showed that the IgG fraction + from sera containing high titre anti-IgE antibody cancw degranulate cutaneous mast cells in situ even thoughi most systemic lupus erythematosus sera cannot ${ }^{-}$ degranulate circulating basophils in vitro. Fur-으 thermore, the avidity or concentration of theseautoantibodies in the circulation may be too low to $\frac{3}{3}$ promote membrane aggregation of IgE. Finally, it may be that the epitope on the IgE molecule ${ }^{\supset}$ reactive with anti-IgE antibodies is not accessible after binding to cell membranes.

In view of the possible role of the mast cell in fibrosis and scleroderma and evidence that anti-IgE? autoantibodies occur in other connective tissue and atopic diseases ${ }^{11-15}$ the current study sought to evaluate the prevalence and possible clinical corre- $\frac{\mathbb{D}}{2}$ lates of these antibodies in various subsets of systemic sclerosis. We found that approximately one 3 third of patients have anti-IgE autoantibodiesirrespective of the extent or duration of clinicalo disease. It is of interest that patients with limited disease appear to have higher mean anti-IgE titres⿳亠二口 than patients with generalised disease $(p<0.05)$, buto the clinical significance of this finding is at present undefined.

In our patients the number of individuals with IgM anti-IgE autoantibodies was not significantlyo different from the number in the control population (Fig. 1). In addition, there was a significant correla음. tion between IgM anti-IgE autoantibodies and totah serum IgE concentrations. It is of interest in this ${ }^{\curvearrowright}$ regard that Williams et al have previously described 0 the existence of IgM anti-IgE autoantibodies that arise naturally. ${ }^{24}$ Furthermore, IgM anti-IgE anti-O bodies appear to have restricted specificity, which iso directed against a non-idiotypic epitope in the $\mathrm{F}(\mathrm{ab})_{2}$ fragment, whereas $\mathrm{IgG}$ anti-IgE appears to 9 be reactive with the $\mathrm{Fc}$ fragment. ${ }^{25}$

Although we were unable to identify any specifico clinical or serological feature associated with the presence of anti-IgE autoantibodies, a role irD disease pathogenesis is not excluded. We are curo rently engaged in a study of a mast cell stabilising agent (ketotifen) to elucidate further the potentiag 
for mast cell modulation of the clinical course in scleroderma.

The authors gratefully acknowledge the secretarial expertise of Myra Ward and Maureen Veprek, and the assistance of William Roth, $\mathrm{PhD}$ and Michael Foster, $\mathrm{PhD}$ for statistical analysis.

\section{References}

1 Claman H N. Mast cells, T cells, and abnormal fibrosis Immunology Today 1985; 6: 192-5.

2 Hawkins R A, Claman H N, Clark R A F, Steigerwald J C. Increased dermal mast cell populations in progressive systemic sclerosis: A link in chronic fibrosis? Ann Intern Med 1985; 102: 182-6.

3 Fonesca E, Solis J. Mast cells in the skin: progressive systemic sclerosis and the toxic oil syndrome. Ann Intern Med 1985; 102 864-5.

4 Claman H N. Mast cell depletion in murine chronic graftversus-host disease. $J$ Invest Dermatol 1985; 84: 246-8.

5 Menton D N, Hess R A, Lichtenstein J R, Eisen A Z. The structure and tensile properties of the skin of tightskin (TSK) mutant mice. $J$ Invest Dermatol 1978; 70: 4-10.

6 Walker M, Harley R, Maize J, DeLustro F, LeRoy E C. Mast cells and their degranulation in the TSK mouse model of scleroderma. Proc Soc Exp Biol Med 1985; 180: 323-8.

7 Walker M A, Harley R A, LeRoy E C. Inhibition of fibrosis in TSK mice by blocking mast cell degranulation. $J$ Rheumatol 1987; 14: 299-301.

8 Kaplan A P, Haak-Frendscho $M$, Fauci A, Dinarello $C$ Halbert E. A histamine releasing factor from activated human mononuclear cells. J Immunol 1985; 135: 2027-32.

9 Fleischmajer R, Perlish J S, Reeves J R T. Cellular infiltrates in scleroderma skin. Arthritis Rheum 1977; 20: 975-84.

10 Atkins F M, Friedman M M, Subba Rao P V, Metcalfe D D. Interactions between mast cells, fibroblasts and connective tissue components. Int Arch Allergy Appl Immunol 1985; 77: 96-102.

11 Gruber B L, Kaufman L D, Marchese M J, et al. Anti-IgE autoantibodies in SLE: prevalence and biologic activity. Arthritis Rheum 1988; 31: 1000-6.
12 Inganas $\mathrm{M}$, Johansson $\mathrm{S} \mathrm{G} \mathrm{O}$, Bennich $\mathrm{H}$. Anti-IgE antibodies in human serum: occurrence and specificity. Int Arch Allergy Appl Immunol 1981; 65: 51-61.

13 Carini C, Fratazzi C, Barbato M. IgG autoantibody to IgE in atopic patients. Ann Allergy 1988; 60: 48-52.

14 Nawata Y, Koike T, Yanagisawa T, et al. Anti-IgE autoantibody in patients with bronchial asthma. Clin Exp Immunol 1984; 58: 348-56.

15 Nawata $Y$, Koike T, Hosokawa H, Tomioka H, Yoshida S. Anti-IgE autoantibody in patients with atopic dermatitis. $J$ Immunol 1985; 135: 478-82.

16 Masi A T, Rodnan G P, Medsger T A, et al. Preliminary criteria for the classification of systemic sclerosis (scleroderma). Arthritis Rheum 1980; 23: 581-90.

17 LeRoy E C, Black C, Fleischmajer R, et al. Scleroderma (systemic sclerosis): classification, subsets and pathogenesis. $J$ Rheumatol 1988; 15: 202-5.

18 Seibold J R, Harris J N. Plasma beta-thromboglobulin in the differential diagnosis of Raynaud's phenomenon. $J$ Rheumatol 1985; 12: 99-103.

19 Lichtenstein L M, Osler A G. Studies on the mechanism of hypersensitivity phenomenon. IX. Histamine release from human leukocyte by ragweed pollen antigens. J Exp Med 1964; 120: $507-17$.

20 Beaven M A, Jacobsen S, Horakova Z. Modification of the enzymatic isotopic assay of histamine and its application to measurement of histamine in tissues, serum, and urine. Clin Chim Acta 1972; 37: 91-6.

21 Franzen L. Further studies on the relationship between druginduced mast-cell secretion and local cell proliferation. Acta Pathologica et Microbiologica Scandinavica. Section A: Pathology 1981; 89: 57-62.

22 Dabrowski R, Szczepanowska A. Alterations in histamine and collagen induced in chick embryos by aminoquidine and $48 / 80$. Agents Actions 1984; 14: 458-60.

23 Metcalfe D D, Kaliner M, Donlon M A. The mast cell. CRC Crit Rev Immunol 1981; 3: 23-74.

24 Williams R C Jr, Griffiths R W, Emmons J D, Field R C. Naturally occurring human antiglobulins with specificity for IgE. J Clin Invest 1972; 51: 955-67.

25 Johansson S G O. Anti-IgE antibodies in human sera. J Allergy Clin Immunol 1986; 77: 555-7. 